\title{
EXPLORING AN OPTIMIZATION STRATEGY AT THE MAINTENANCE DEPARTMENT OF AN OIL COMPANY Stefan Harrison ${ }^{1 *}$, Jainarine Bansee ${ }^{2}$, Boppana Chowdary ${ }^{3}$, Rajeev Seepersad and Dillon Frederick
}

\author{
1,2,3 Faculty of Engineering, The University of the West Indies, \\ Trinidad ${ }^{1}$ Email: stefan.harrison@sta.uwi.edu*(Corresponding author) \\ ${ }^{2}$ Email: jainarine.bansee@sta.uwi.edu \\ ${ }^{3}$ Email: boppana.chowdary@sta.uwi.edu \\ Email: rajeev.seepersad@gmail.com \\ Email: dillonfrederick7@hotmail.com
}

\begin{abstract}
This paper looks at applying predictive maintenance and automated data storage and retrieval to reduce waste within a Petroleum Company. In this company, all pump maintenance was performed internally. The study explores the potential effect of the proposed strategy on the operations of three departments relevant to pump maintenance. These departments were, the Pump Shop, Stores Department and Shipping and Receiving. Rockwell Automation's Arena ${ }^{\circledR}$ simulation software was used to model an existing and proposed maintenance system comprised of these three departments and track the performance measures of Flow Time, Waiting Time and Work-in-Process. Analysis of the performance measures revealed a significant reduction in average Flow Time and Waiting Time by $76 \%$ and $96 \%$ respectively with no significant change to Work-in-Process.
\end{abstract}

Keywords: Data Storage and Retrieval, Predictive Maintenance, Discrete Event Simulation, Case Study.

https://doi.org/10.47412/GXHP6799

\section{Introduction}

\subsection{Background}

The general oversupply of crude oil, which started in 2014 and extended into 2016, Fig. 1.1, led to a fall in global oil prices [1]. The main causes were firstly, new production techniques that allowed for unprecedented production growth in the North American shale oil industry. The United States of America for example, increased oil production from around 5 million barrels per day in 2008 to over 9 million barrels in 2015 [2]. Secondly, the Financial Crisis of 2007 - 2008, and the following Great Recession of 2008 2013, caused a weakening of the world economy and reduced capital expenditure [1]. Finally, changing government policies in developed nations also served to reduce the growth of demand for foreign oil [2]. These events contributed to a crisis for numerous oil-producing countries due to decreased revenues.

In January 2017, OPEC and non-OPEC oil producers jointly agreed to supply cuts in an effort to arrest the fall of oil prices and rebalance the global market [3]. However, the intrinsic volatility of the global oil market means that many oil companies continue to maintain capital discipline with focus placed on productivity improvements and new advances in technology. For the period of $2017-2018$, statistics at the oil company showed that more than $\$ 188$ million dollars were spent on overtime payments to its employees. 
The reduction of overtime related to maintenance activities is therefore one way of improving the firm's productivity.

This paper seeks to apply a lean approach to the operations of an oil company within the Caribbean region. The subject of the study is the company's pump maintenance and repair job shop, referred to in text as the Pump Shop. The format of this paper is as follows: Section 1 introduces the issue faced by the oil company, it reviews the literature regarding the proposed improvement strategy and discusses the study's methodology. Section 2 introduces the case study investigated and discusses the process of model formulation. It includes the collection and analysis of data, assumptions and limitations of the study, the design of the existing model and the generation of the proposed model. Section 3 presents the results of the study and discusses their significance. Finally, Section 4 presents the concluding remarks and offers avenues for future work.

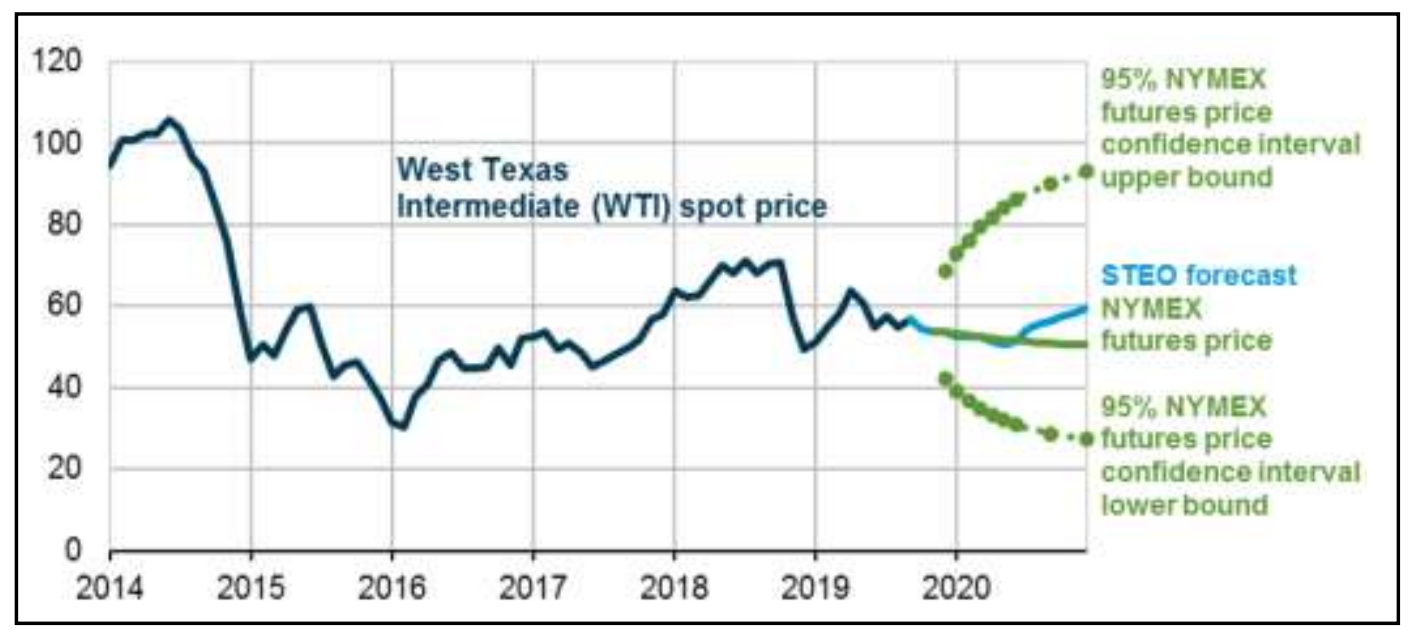

Figure 1.1: West Texas Intermediate crude oil price.

Source: U.S. Energy Information Administration, 2019. West Texas Intermediate (WTI) Crude oil Price and NYMEX confidence intervals dollars per barrel.

\subsection{Research Methodology}

The value stream of the Pump Shop and related processes in the Stores and Shipping and Receiving departments were mapped while in consultation with system experts. Key PM were also identified and recorded during this process. This information was used to develop the functional specifications of the system and a model representing its existing state, referred to in text as the existing model, was constructed and verified under control conditions. Statistical distributions that best fit the collected data were used to represent the inter-arrival time (IAT), number of arriving entities and processing times. The PM outputs of the existing model were then validated by system experts as corresponding to observed metrics.

A proposed model incorporating elements of the suggested optimization strategy was then generated. With consideration to available computing resources, the desired precision of reported PM, $h$, was used to determine $n_{e}$, the number of replications performed by the existing and proposed models. The value of $n_{e}$ was estimated using Eq. (1) where $n_{0}$ was the number of replications required to derive half-width $h_{0}$ [4].

$$
n_{e}=n_{0} \frac{h_{0}^{2}}{h^{2}}
$$


The output PM of the existing and proposed models were compared and tested for significant differences through independent samples t-tests conducted using SPSS. The results of the study and conclusions drawn were documented within this paper.

\subsection{Literature Review}

On a global level, manufacturers are not able to utilize their existing production capacity to a satisfactory standard. The average Overall Equipment Efficiency (OEE) in the manufacturing industry is around 55\% [5]. It follows that equipment downtime is a major point of interest for many companies due to its direct impact on productivity. Devising strategies for maintenance practices that improve efficiency in production systems is therefore a vital task for local manufacturers seeking to achieve a competitive edge in global markets. A lean approach to maintenance has the potential to improving a firm's OEE [6].

Predictive maintenance is one way of affecting machine utilization. This involves determining when servicing operations are required by monitoring, in real time, the condition of machines and analysing the relationship between multiple parameters and part degradation [7]. On-board intelligent alarm systems, networked condition monitoring devices; and the analysis of historical data by trained personnel are all tools required by an effective predictive maintenance program [8] [9].

The automation of data storage and retrieval is another possible means of optimization. This can be accomplished by integrating maintenance procedures into a firm's Enterprise Resource Planning (ERP) system [10]. Tools and devices such as barcodes and radio frequency identification (RFID) tags may also automate data entry and retrieval [11] [12] [13]. When applied to predictive maintenance, such systems can allow for the dynamic adjustment of maintenance scheduling, purchasing, inventory and production in response to changing operational conditions based on historical data [14]. The following case study models the effects of the proposed optimization strategy.

\section{Case Study}

\subsection{System Definition}

Within the company, the repair process of failed pumps and other related maintenance activities is performed internally at the Pump Shop of the maintenance department, Fig. 2.1. Failed pumps and those scheduled for maintenance are delivered to the Pump Shop along with a matching work order. Each machine is then assessed for the root cause of its failure and repaired accordingly. Repairs are conducted following the American Petroleum Institute (API) standards and OEM specifications under the safety guidelines of the company's Job Hazard Analysis and Health, Safety and Environment (HSE) procedures. On identifying failed parts, a request is then sent to the Stores Department via a hand written card. This request identifies the spare parts required or the materials needed to fabricate a replacement.

On receiving such a request, clerks at the Stores Department then proceed to locate the ordered parts or materials within the company's storage facility. Upon location, parts are sent via a driver or messenger to the Pump Shop along with a Delivery Note that must be signed by the employee responsible for receiving items. In the event that the parts are not available at the Stores Department, a Request to Purchase is sent to the Procurement Department, which then orders the parts. The Request to Purchase is a document which contains information about the parts required, this includes part specifications and the details of the job that the part is intended to be used for. Once parts are ordered, the Stores Department is then notified of the delivery date via telephone. On delivery of purchased parts, the Stores Department immediately sends the items to the Pump Shop. The parts sent are kept by the Shop Supervisor, who is responsible for providing Pump Technicians with their requested equipment. The processes of part installation, rebuilding and hydro 
testing of pumps are then scheduled for the technicians assigned to the job. Once the Pump Technicians report to their supervisor that a job is complete, the pumps are then transported out of the Pump Shop.

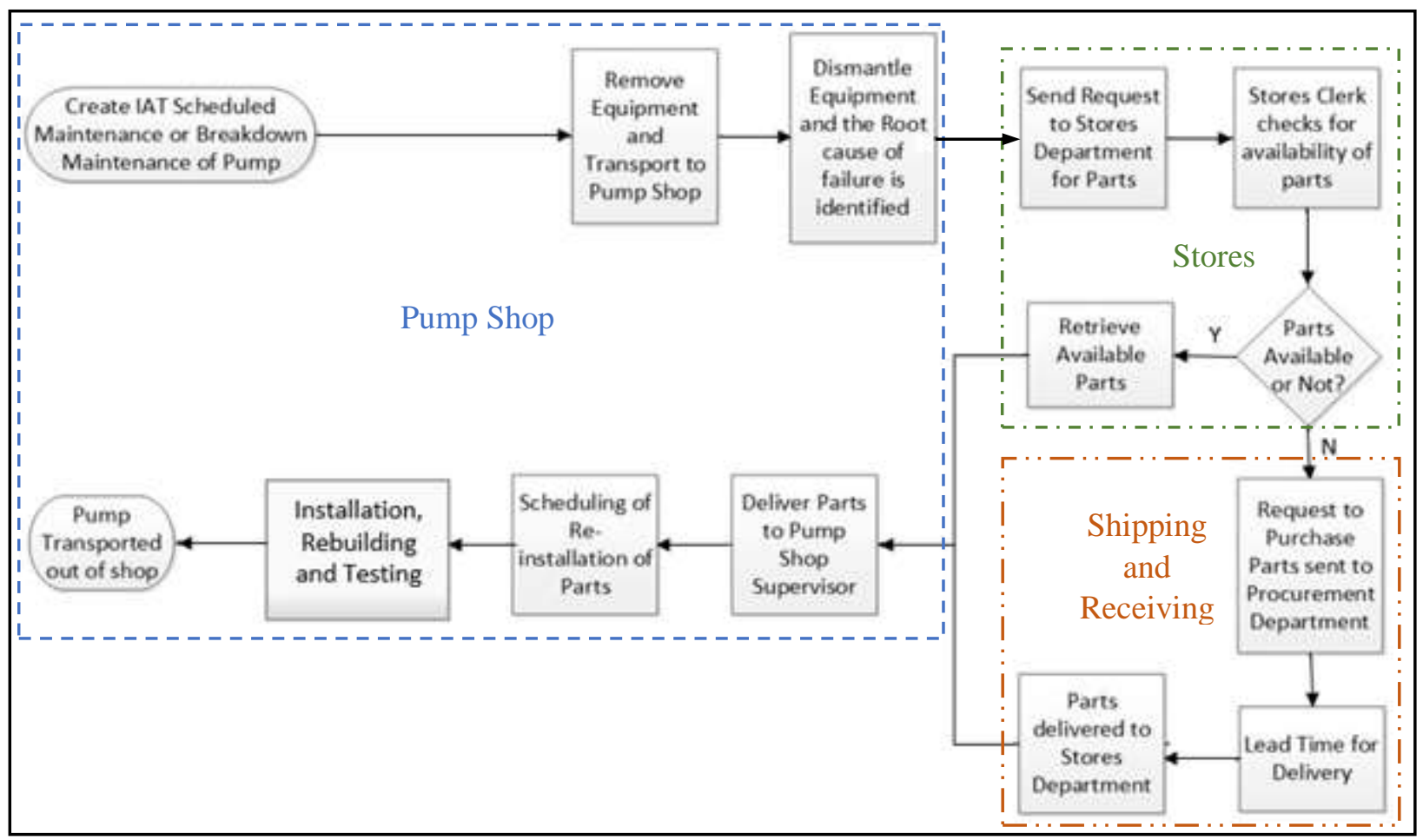

Figure 2.1: Process flowchart of pump maintenance activities.

\subsection{Model Formulation}

\subsubsection{Input Data Collection and Analysis}

Based on data collected over an eleven (11) month period, Table 1, statistical distributions for the IAT and the number of incoming pumps were determined using Rockwell Automation's Input Analyzer ${ }^{\circledR}$ software. These Weibull Distributions, Eq. (2), Eq. (3), were used in the existing model to represent the frequency and number of pumps undergoing the maintenance process. Data regarding process times were also recorded at various stages of the system. This data was analysed using the Input Analyser ${ }^{\circledR}$ tool and used to determine the time distributions for the repair processes listed in Table 2. 
Table 18: Extract from the data collected regarding pump arrivals.

\begin{tabular}{cccccc}
\hline $\begin{array}{c}\text { Pump Arrival } \\
\text { [Week] }\end{array}$ & IAT [Hours] & $\begin{array}{c}\text { No. of } \\
\text { Pumps }\end{array}$ & Start Date & Finish Date & Service Time [Hours] \\
\hline 1 & 0 & 1 & $23 / 01 / 2013$ & $25 / 01 / 2013$ & 29.5 \\
\hline 2 & 40 & 1 & $28 / 01 / 2013$ & $30 / 01 / 2013$ & 29.6 \\
\hline 3 & 72 & 1 & $06 / 02 / 2013$ & $08 / 02 / 2013$ & 28.8 \\
\hline 4 & 64 & 1 & $14 / 02 / 2013$ & $18 / 02 / 2013$ & 26.1 \\
\hline 4 & 8 & 1 & $15 / 02 / 2013$ & $19 / 02 / 2013$ & 30.8 \\
\hline 5 & 32 & 1 & $19 / 02 / 2013$ & $19 / 02 / 2013$ & 32.3 \\
\hline 6 & 48 & 1 & $25 / 02 / 2013$ & $27 / 02 / 2013$ & 33.1 \\
\hline 6 & 16 & 1 & $27 / 02 / 2013$ & $01 / 03 / 2013$ & 31.0 \\
\hline 12 & 344 & 1 & $11 / 04 / 2013$ & $19 / 04 / 2013$ & 32.5 \\
\hline 13 & 48 & 1 & $17 / 04 / 2013$ & $02 / 05 / 2013$ & 32.6 \\
\hline
\end{tabular}

$$
\begin{array}{r}
\text { IAT Distribution }=8+\operatorname{WEIB}(50.3,0.623) \\
\text { Number of Incoming Pumps }=0.5+\operatorname{WEIB}(0.804,1.92)
\end{array}
$$

Table 19: Processes and Processing Time Distributions

\begin{tabular}{ll}
\hline \multicolumn{1}{c}{ Process } & Processing Time Distribution \\
\hline Check for availability of parts/materials (hours) & $\operatorname{NORM}(5.39,2.04)$ \\
\hline Order placed for part/material (hours) & $\operatorname{TRIA}(1.09,5.86,10.9)$ \\
\hline Lead time for ordered part (expedited) (days) & $\operatorname{TRIA}(6.5,13.1,22.5)$ \\
\hline Available part/material delivered to shop (hours) & $\operatorname{TRIA}(1.18,2.09,2.6)$ \\
\hline Inspection (minutes) & $\operatorname{TRIA}(10,16.8,19)$ \\
\hline Recording Receipt (minutes) & $\operatorname{NORM}(20,4.97)$ \\
\hline Transport to storage address (minutes) & $15+17 * \operatorname{BETA}(1.99,1.5)$ \\
\hline Disassembly and Diagnosis of equipment (hours) & $\operatorname{NORM}(2.98,0.093)$ \\
\hline Assembling repaired equipment (hours) & $1.48+3.52 * \mathrm{BETA}(3.43,5.08)$ \\
\hline Machine Setup (hours) & $\operatorname{NORM}(1.02,0.182)$ \\
\hline Part Processing (hours) & $\operatorname{TRIA}(2,4.33,6)$ \\
\hline Part Post Processing (hours) & $0.34+\mathrm{WEIB}(1.25,4.29)$ \\
\hline Work order travel time from Pump Shop to Stores (hours) & $0.44+1.37 * \mathrm{BETA}(2.95,2.91)$ \\
\hline
\end{tabular}

\subsubsection{Assumptions and Limitations}

The following assumptions and limitations were applied to the existing and proposed models created:

- All materials entering the Machine Shop for any particular pump were treated as one job.

- Parts were categorized as either good, or bad.

- Variations in the type of parts and materials were not considered.

- The distance travelled by the parts removed from the disassembly area was not considered.

- The variations in the type and model of pumps entering the system was not considered.

- Suppliers were assumed to provide reliable service of an acceptable standard to the company. 


\subsubsection{Design of Existing Model}

By applying Eq. (1) to the models it was determined that 2,190 replications were required to achieve the desired degree of precision. Due to the nature of the Pump Shop, where a preventative maintenance schedule ensured continuous activity, the existing model was designed to be a non-terminating simulation. The run length of the model was set at 90 days, which consisted of 8 hour work days, to allow the system to achieve steady state conditions [4].

Truncated replications were utilized to prevent initialisation bias from affecting the reported metrics. This was done through the application of a 25 day warm up period. This warm up period was determined by using Arena Output Analyzer® to plot a graph of time dependent performance metrics over the 90 day period. Through examination of the plot, 25 days was conservatively estimated as the time after which the system entered steady-state conditions [4]. The existing model was created using the modules described within Table 3 with application of the initial conditions as described and the limits and assumptions listed in Section 2.2.2.

Table 20: Notable Arena ${ }^{\circledR}$ Modules and descriptions of their usage in the Existing Model.

Create A create module was used in the Existing system to simulate the arrival of pumps into the Pump Shop, Fig. 2.2. The statistical distributions for IAT, Eq. (1); and quantity of incoming pumps, Eq. (2), were determined by using Arena Input Analyser ${ }^{\circledR}$ on the data provided in Table 1 . The results were input into the model.

Decide These modules determined the specific series of processes an entity passed through on entering the existing system. They were used for example to differentiate whether a part was available in the Inventory by comparing the number of parts requested to the quantity held in the inventory.

Route This module transferred entities to a user-specified station and included the option of defining a transfer delay. For example, work orders requesting parts and materials from the Stores Department were transferred by Route Module, "Route to Stores", Fig. 2.2, to the specified Station.

Station Station Modules defined areas which corresponded to the physical or logical location where processing occurred and in Arena ${ }^{\circledR}$, were the locations to which route modules sent entities. For example, the Station Module, "Machine Shop", Fig. 2.2, received materials routed from a location in model that represented the stores department.

Separate This module was used to duplicate an incoming entity and transfer the copy to other areas of the model. For example, the Separate Module, "Separate Good and Bad Parts" duplicated entities which were passed on to other processes as either 'good' or 'bad' parts Fig. 2.2.

Hold This module was used to detain an entity in a queue until a specified condition is fulfilled. For example, work orders were detained in a Hold Module until parts or materials were reordered.

Match A Match Module brings together a specified number of entities waiting in different queues. Match Module, "Match Parts" was used in this model to represent the matching of original pump parts to new replacements. The parts were then permanently grouped together and released as a single entity Fig. 2.2.

Dispose This module removes entities from the system and may record entity statistics before the entity is disposed. Repaired pumps exited the system via Dispose Module, "Equipment Out" shown in Fig. 2.2. 
Label This module was used to define a specific label. Labels were used to relocate an entity from one area of a model to another without the use of connectors.

Assign The assign modules were used to alter variables within the system or attach and modify entity specific attributes. For example, Assign Module, “Assign ID”, Fig 2.2, gave the attribute "a_ID" to pumps which allowed the model to make decisions based on that attribute's value.

Process The Process Modules detailed the operations performed on an entity over a specified time period utilizing resources. They were categorised in the models as either value added (VA) or non-value added (NVA). The "Assemble" Process Module, Fig 2.2, represents the reconstruction of pumps with parts that have been replaced or repaired.

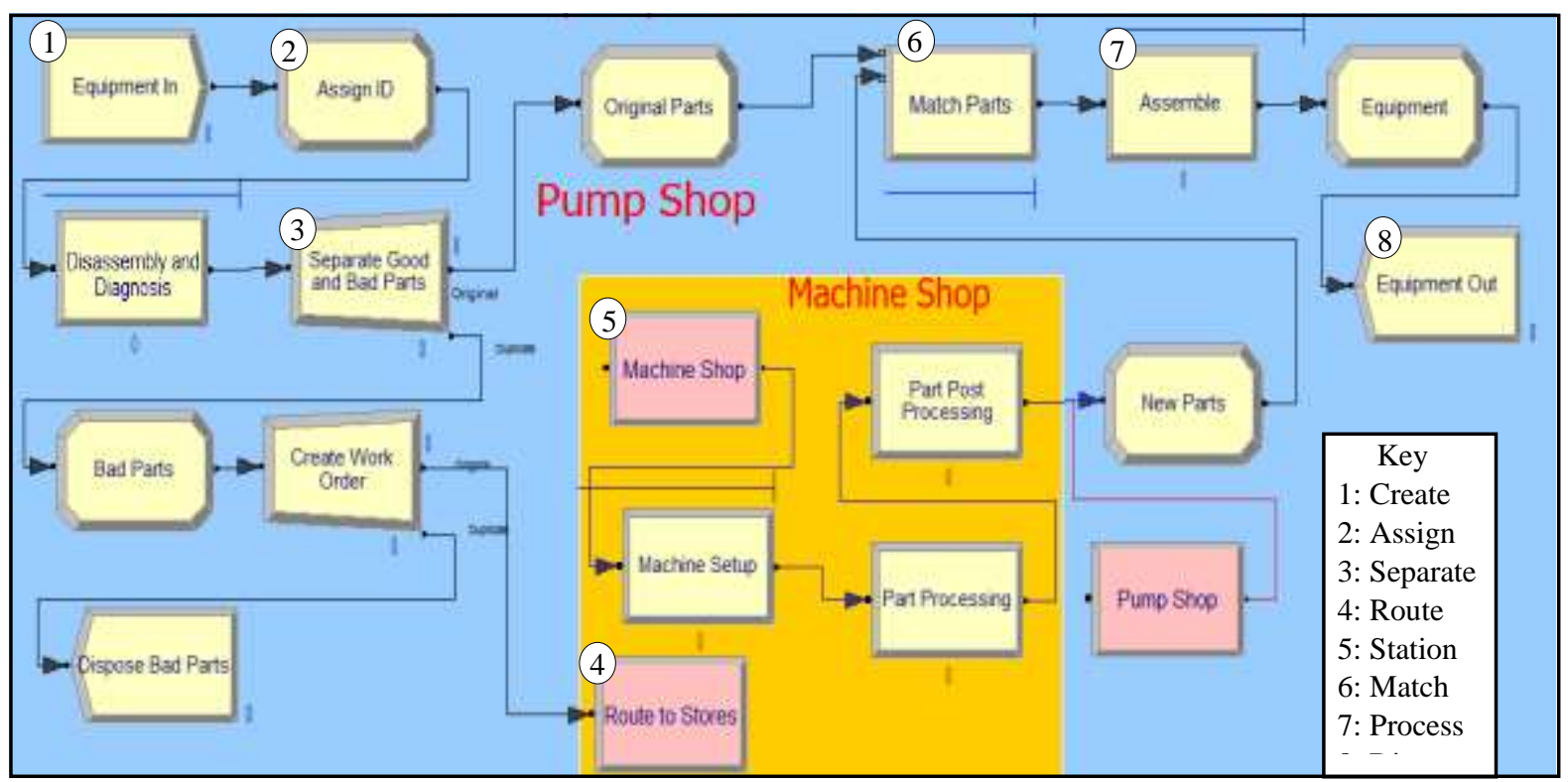

Figure 2.2: Extract from Existing Model, Pump Shop. Pump repair processes.

\subsubsection{Generation of Proposed Model}

A proposed model was created by applying the suggested strategy to the existing system. First, the use of an automated data storage and retrieval system was modelled as a reduction in the time spent on data entry and information retrieval tasks such as searching for a part's storage location. Second, the effect of a predictive maintenance practice was reproduced in the model by having arriving entities first enter the model at Stores department in the form of a parts request. This represented a process where the analysis of historical and condition monitoring data allowed the maintenance department to predict the likely occurrence of machine failure modes. This ensured that the parts and materials required for repairs were secured prior to the initiation of maintenance activities. The initial conditions of IAT, quantity of pumps on arrival, run length, number of replications and warm up period remained identical to the existing model. 
Table 21: Notable Arena ${ }^{\circledR}$ Modules in Proposed Model and descriptions of their usage.

\begin{tabular}{ll}
\hline Create & $\begin{array}{l}\text { The create module was used in the Proposed Model to simulate the production of a predictive } \\
\text { maintenance schedule. The distributions for IAT and quantity on arrival were identical to those } \\
\text { used in the existing system. This module created work orders that first entered the Stores } \\
\text { department, Fig. 2.3, before eventually being transferred to the Pump Shop Fig. 2.4. }\end{array}$ \\
\hline Clone & $\begin{array}{l}\text { This module was used to duplicate an incoming entity and transfer the copy to specified Labels } \\
\text { at other areas of the model. Clones of completed work orders entered the Pump Shop as pumps. }\end{array}$ \\
\hline Label & $\begin{array}{l}\text { Pumps entered the Pump Shop only after replacement parts were confirmed to be available. } \\
\text { The Create Module in Fig. 2.2 was replaced by a Label Module in the proposed system. Pump } \\
\text { Repair Plans entered the Pump Shop through a Label Module Fig. 2.4. }\end{array}$
\end{tabular}

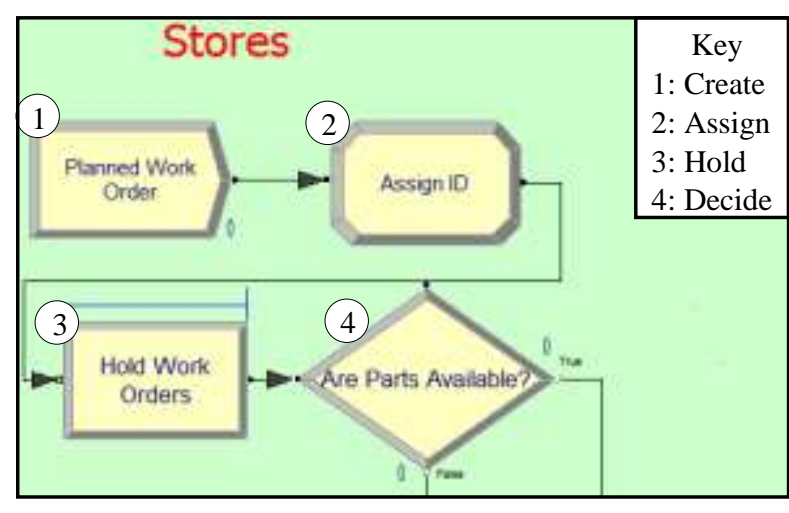

Figure 2.4: Extract from Proposed Model, Stores

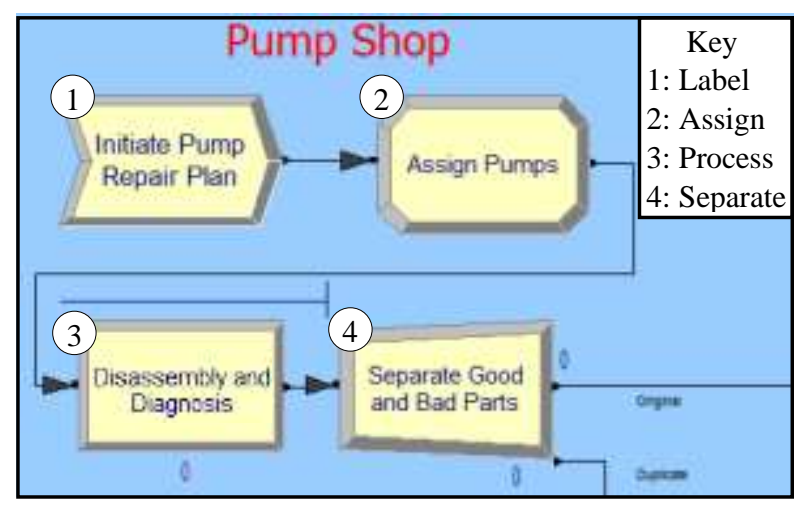

Figure 2.3: Extract from Proposed Model, Stores

\section{Results and Discussion}

The performance metrics output by Arena ${ }^{\circledR}$ for the existing and proposed models were summarised in Table 5.

Table 22: Performance Metrics of the Existing and Proposed Models

\begin{tabular}{cccc}
\hline Performance Metrics & Existing Model & Proposed Model & Precision \\
\hline Waiting Time & 28 & 1 & \pm 1 hour \\
\hline Flow Time & 38 & 9 & \pm 1 hour \\
\hline WIP & 1 & 1 & \pm 1 pump \\
\hline
\end{tabular}

The comparison of the existing and the proposed models revealed a reduction in average FT and WT, from 28 to $1 \pm 1$ hour and 38 to $9 \pm 1$ hour, respectively while the average WIP is unchanged, Table 5 . Independent samples t-tests determined a significant difference between the reported WT of the existing model $(\mathrm{M}=22.28, \mathrm{SD}=10.94)$ and proposed model $(\mathrm{M}=0.64, \mathrm{SD}=1.17) ; \mathrm{t}(29.66)=10.77, \mathrm{p}<0.001$. A significant difference was also noted in the FT of the existing model $(\mathrm{M}=34.96, \mathrm{SD}=15.94)$ and proposed model $(\mathrm{M}=9.99, \mathrm{SD}=2.12) ; \mathrm{t}(30.03)=8.51, \mathrm{p}<0.001$. WIP was found to not be statistically significant at the $95 \%$ confidence interval used for the three t-tests.

From these results it was determined that the implemented strategy likely allowed for a significant reduction in the average time that pumps were down due to maintenance. The automation of data storage and retrieval reduced the time pumps waited for the completion of setup related activities in the Stores and Shipping and 
Receiving departments. The predictive maintenance plan further contributed to time savings by allowing parts and materials to be secured prior to initiating repair activities at the Pump Shop. However, the success of the predictive maintenance plan was based on the assumption that maintenance personnel correctly predicted pump failure modes with sufficient lead time for obtaining the parts and materials needed for repairs.

\section{Conclusion and Future Work}

This research was aimed at optimizing the existing Pump Shop, Stores and Shipping and Receiving Departments of a large Petroleum company. It compared the performance metrics of FT, WT and WIP between the existing and proposed models using Rockwell Automations Arena® Simulation software and determined the observed significant differences through statistical testing. The study showed how the measures proposed resulted in the significant reduction in average FT and WT by $76 \%$ and $96 \%$ respectively. The models indicated a likely improvement in operations as a result of a reduction in machine downtime due to maintenance activities without significant changes to WIP. It should be noted however, that the systems modelled did not take into account the variability in the models of pumps maintained or the differences in the families of parts or materials required.

The use of an automated data storage and retrieval system contributed to the improved FT and WT by reducing time spent on non-value-added tasks. However, this was based on the assumption that the relevant departments were able to be easily integrated into the company's existing ERP system. The predictive maintenance plan also reduced FT and WT as a result of having the required parts and materials available due to early fault detection. This element of the proposed strategy assumed that the Pump Shop would have the trained staff and data to accurately forecast machine failures and detect the type of fault likely to occur. It was also assumed that there would be sufficient lead time to procure necessary parts prior to machine failure.

Areas of future work related to this study include:

- The reliability of local suppliers to support maintenance operations across the variety or parts, materials and models of pumps.

- The effect of Just-in-Time manufacturing as a proposed strategy.

- The feasibility of implementing the automated data storage and retrieval system and integrating Maintenance, Stores, and the Shipping and Receiving Departments into the company's existing ERP system.

- A study into the effectiveness of discrete event simulation to investigate optimising maintenance operations of a larger sample of local manufacturing firms. 


\section{References}

[1] International Energy Agency. 2019. The Impact of the Financial and Economic Crisis on Global Energy Investment. International Energy Agency.

[2] J. V. Mitchell and B. Mitchell. Structural crisis in the oil and gas industry. In Energy Policy 64, (2014) 36-42. https://doi.org/10.1016/j.enpol.2013.07.094

[3] T. van de Graaf and B. Michael. Stranded wealth: rethinking the politics of oil in an age of abundance. International Affairs 94, no. 6, (2018) 1309-1328. DOI: 10.1093/ia/iiy 197.

[4] W.D. Kelton, R. P. Sadowski and N. B. Zupick. Simulation with Arena. $6^{\text {th }}$ ed. New York: McGraw Hill, 2015.

[5] M. Gopalakrishnan, A. Skoogh and C. Laroque (2013). 'Simulation-Based Planning of Maintenance Activities in the Automotive Industry'. In Proceedings of the 2013 Winter Simulation Conference. J.W. Marriott Hotel, Washington, D. C. USA. (pp. 2610-2621). IEEE.

[6] A. En-Nhaili, A. Meddaoui and D. Bouami. Effectiveness improvement approach basing on OEE and lean maintenance tools. International Journal of Process Management and Benchmarking 6, no. 2 (2016) 147-169.

[7] J. Santos, R. Wysk and J.M. Torres, 2006. Improving Production with Lean Thinking. John Wiley \& Sons, Inc. DOI: 10.1002/9781118984031

[8] J. Gavigan and S. Larson. 2016. Utilizing PI Data to Enhance Maintenance and Reliability Program. 2016 SMRP Annual Conference. Society for Maintenance and Reliability Professionals. SMRP.

[9] E. Gilabert, and A. Arnaiz. Intelligent automation systems for predictive maintenance: A case study. Robotics and Computer-Integrated Manufacturing 22 no. 5, (2006) 543-549.

[10] I. Shohet, and L. Nobili. Enterprise resource planning system for performance-based-maintenance of clinics. Automation in Construction 65 (2016) 33-41. https://doi.org/10.1016/j.autcon.2016.01.008

[11] B. Eckfeldt. What does RFID Do for the Consumer? Communication of the ACM 48, no. 9, (2005) 7779.

[12] G. Borriello. RFID: Tagging the World. Guest Editorial to RFID Special Issue. Communications of the ACM. 48, no. 9, (2005) 34-37.

[13] J. Chongwatpol and R. Sharda. Achieving Lean Objectives through RFID: A Simulation-Based Assessment. Decision Sciences 44, no.2, (2013) 239-266.

[14] P. Cassingham, and D. Allen (2008). 'Mining the Corporate Data Domain Safely and Securely Across the Enterprise’. Electric Energy T\&D Magazine, March 2008 Issue. Terrebonne, Quebec Canada. 